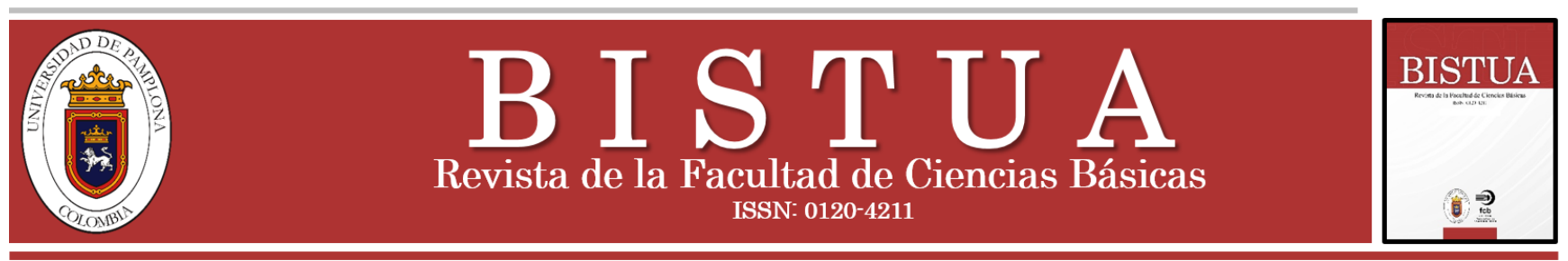

http://revistas.unipamplona.edu.co/ojs_viceinves/index.php/BISTUA

\title{
Citric Acid Recovery from a Synthetic Fermentation Broth by Ion- Exchange Resins
}

\author{
Recuperación de ácido cítrico a partir de un caldo de fermentación sintético por medio de \\ resinas de intercambio iónico \\ Carlos Jacinto ${ }^{a}$; Erick Ramos ${ }^{a}$; Dora López ${ }^{b}$ \\ ${ }^{a}$ Universidad Centroamericana José Simeón Cañas, El Salvador \\ ${ }^{b}$ Latinoamérica Renovable, USA. \\ Contacto: Carlos Jacinto - 00037615@uca.edu.sv
}

Recibido: Diciembre 17, 2020. Aceptado: Diciembre 28, 2020

https://doi.org/10.24054/01204211.v2.n2.2020.4437

\begin{abstract}
An adsorption method with Dowex ${ }^{\mathrm{TM}}$ Marathon $^{\mathrm{TM}}$ WBA resin has been developed in order to evaluate citric acid recovery produced by submerged fermentation. To determine the viability of this separation method, the resin was tested at different conditions of temperature $\left(30-70{ }^{\circ} \mathrm{C}\right)$ and $\mathrm{pH}(1.5-6.5)$. The results showed that lower $\mathrm{pH}$ improves the adsorption of citric acid of which the $85 \%$ can be recovered with a purity of $92 \%$. This represent a maximum adsorption capacity of $0.46 \mathrm{~g}$ of citric acid per gram of used resin.
\end{abstract}

Keywords: Citric acid, ion-exchange resin, adsorption, fermentation broth.

\section{Introduction}

Citric acid is one of the most demanded carboxylic acids in the global food, pharmaceuticals, and biodegradable plastic markets [1]. Worldwide projections indicate a rise in the demand of citric acid and its production [2]. According to estimations, the market value of citric acid will continue to grow and will soon exceed US\$2 billion [3]. Because of this, different methods for its production and recovery have been tested. The most common method for industrial production of citric acid consists in submerged fermentation using Aspergillus niger, by the conversion of different types of substrates, such as sugarcane molasses, beet molasses, potato peels, sugar, among others [4].

Because of the general use of Aspergillus niger for citric acid production in submerged fermentations, various recovery methods of the acid present in fermentation broths have been developed [5]-[9]. One of the most commonly used methods is the recovery of citric acid by precipitation as

\section{Resumen}

Un método de adsorción utilizando la resina Dowex ${ }^{\mathrm{TM}}$ Marathon ${ }^{\mathrm{TM}}$ WBA ha sido desarrollado con el fin de evaluar la recuperación de ácido cítrico producido por fermentación sumergida. Para determinar la viabilidad de este método de separación, la resina fue evaluada a diferentes condiciones de temperatura $\left(30-70{ }^{\circ} \mathrm{C}\right)$ y $\mathrm{pH}(1.5-6.5)$. Los resultados mostraron que a pH bajo, se mejora la adsorción de ácido cítrico, a través de la cual, se recupera el $85 \%$ del ácido y se obtiene una pureza del $92 \%$. Esto representa una capacidad máxima de adsorción de $0.46 \mathrm{~g}$ de ácido cítrico por gramo de resina empleada.

Palabras clave: ácido cítrico, resina de intercambio iónico, adsorción, caldo de fermentación.

calcium citrate and its further regeneration by the addition of sulfuric acid [1]. Recovered citric acid in solution is then purified and crystalized for its commercialization [10]. The main problem with this method is the high production of lowvalue residues, since for each kilogram of citric acid that is produced, forty kilograms of waste water and two kilograms of gypsum are generated [5], [11], [12]. Additionally, solvent extraction has been tested for citric acid recovery showing satisfactory results [13]. However, due to its environmental impact and the high cost of the solvents, this method has not been scaled up [5], [14]. Another method for citric acid recovery is electrodialysis and membrane separation; however, viability of this method is still subject of study [11], [12], [15], [16]. The relatively short life of the membranes and the high energetic demand of the electrodialysis compared to the traditional recovery method by precipitation make this method less convenient for industrial applications [17], [18]. 
In recent years, citric acid recovery by adsorption methods has been widely studied due to the high recovery rates, reduced waste generation and low energy consumption [5]. Furthermore, one of the main advantages of the adsorption method lies in the simplification of the recovery technology, since no specialized equipment other than a separation column and a set of pumps is required [19]. The adsorption method is based on the retention capacity of a specific compound by ion-exchange resins. This specificity quality is due to the chemical design of resins in order to make them highly effective in the retention of citric acid while in contact with the process streams [18]. In previous studies, the adsorption capacity of resins has been tested in the recovery of citric acid and promising results have been achieved [5], [18], [20].

Resins have a wide range of application due to the diversity of compounds that are capable to retain. Their use consist in the selective adsorption of the compound of interest present in a mixture [20]-[24] (for example, lactic acid [20], [25], phenolic acids [26], lactoperoxidase [27], and longchain fatty acids [28], [29]). The resins can be regenerated using a solution capable of exchanging the acid adsorbed, allowing its reuse [5], [18]. For citric acid, most efficient adsorption has been achieved using resins that present weak anionic exchange [1], [20]. In this type of anion exchangers, amines (as characteristic functional group) present higher efficiencies in the retention of organic acids, and specially citric acid, due to the formation of an acid-ammine complex [17], [21], [22], [25]. The versatility of amine resins allows their use in a wide range of $\mathrm{pH}$ and temperature conditions, maintaining their stability under most common processing conditions, and in the recovery of various compounds [30]. Among these resins, Dowex ${ }^{\mathrm{TM}}$ Marathon ${ }^{\mathrm{TM}}$ WBA and Dowex $^{\mathrm{TM}}$ Marathon $^{\mathrm{TM}}$ MSA are amine resins commonly used in water demineralization; technetium, uranium and iron recovery [21], [23], [24]; lactic acid recovery [6]; and ionic liquids purification [22]. The main differences between the resins are that the WBA is a weak base anion resin while the MSA is a strong base anion resin. In addition, the functional group of thw WBA is dimethylamine while the MSA has a quaternary amine in its structure. Despite the amount of studies related to these types or resins, detailed and specific studies of their citric acid adsorption capacity in complex mixtures have not been developed.

In the present work, the adsorption capacities of the Dowex $^{\mathrm{TM}}$ Marathon ${ }^{\mathrm{TM}}$ WBA and the Dowex ${ }^{\mathrm{TM}}$ Marathon $^{\mathrm{TM}}$ MSA were evaluated. Additionally, various test were done to the resins in order to evaluate their applicability in the recovery of citric acid from a synthetic fermentation broth.

\section{Materials and methods}

\subsection{Materials}

For the experiments, Dowex ${ }^{\mathrm{TM}}$ MARATHON ${ }^{\mathrm{TM}} \mathrm{WBA}$ and MSA ion-exchange resins were employed. The WBA (Weak
Base Anion) resin is a macroporous resin composed by a styrene-divinylbenzene matrix and its functional group is a dimethylamine. According to the manufacturer, its total exchange capacity was $1.3 \mathrm{eq} / \mathrm{L}$, its water content ranges from 50 to $60 \%$ and its shipping weight was $640 \mathrm{~g} / \mathrm{L}$. The MSA (Macroporous Strong Base Anion) resin is a macroporous resin composed by a styrene-divinylbenzene matrix and its functional group is a quaternary amine. According to the manufacturer, its total exchange capacity is $1.1 \mathrm{eq} / \mathrm{L}$, its water content ranges from 56 to $66 \%$ and its shipping weight is $670 \mathrm{~g} / \mathrm{L}$. For all the experiments, reagent grade mono hydrated citric acid was used. Sucrose, glutamic acid, $\mathrm{MgSO}_{4}, \mathrm{Fe}_{2}\left(\mathrm{SO}_{4}\right)_{3},\left(\mathrm{Ca}\left(\mathrm{H}_{2} \mathrm{PO}_{4}\right)_{2}\right), \mathrm{K}_{2} \mathrm{SO}_{4}$ were used in the preparation of the synthetic broth. All reagents were ACS grade. Sulfuric acid and water employed as mobile phase were HPLC grade. Sigma-Aldrich, MO, manufactured sucrose and J. T. Baker Chemical Company, PA., manufactured all other reagents.

\subsection{Preliminary Adsorption Tests}

To select the most suitable resin for the process, both WBA and MSA resin were tested. This initial test tried to determine the highest adsorption capacity between both resins to choose one of them for the remaining experiments. For each type of resin, ten vials were prepared with $5 \mathrm{~g}$ of resin inside each of them. Then, $25 \mathrm{~mL}$ of citric acid solution $(4 \% \mathrm{~m} / \mathrm{v})$ were poured into each vial. The vials were placed in an orbital shaker at $100 \mathrm{rpm}$ and room temperature $\left(25^{\circ} \mathrm{C}\right)$. For both types of resins, $4 \mathrm{~mL}$ samples were taken from each vial on different times during the experiment that lasted 25 minutes. Then, the samples were diluted inside a volumetric flask until reaching $100 \mathrm{~mL}$ to be analyzed using HPLC to obtain the concentration of citric acid in solution. The difference in the concentration of citric acid at the beginning and the end of the adsorption process was determined and Dowex $^{\mathrm{TM}}$ MARATHON $^{\mathrm{TM}}$ WBA resin was selected for further tests.

\subsection{Adsorption capacity of the resin}

Total adsorption capacity of the Dowex ${ }^{\mathrm{TM}}$ MARATHON $^{\text {TM }}$ WBA resin was determined by preparing 10 vials containing $3.2 \mathrm{~g}$ of resin. Aqueous solutions with different concentrations of citric acid (from 1 to $8 \% \mathrm{~m} / \mathrm{v}$ ) were prepared. Then, $25 \mathrm{~mL}$ of each solution were poured into each vial. The vials containing resin and citric acid solution were placed on an orbital shaker at $100 \mathrm{rpm}$ and room temperature $\left(25^{\circ} \mathrm{C}\right)$ for 24 hours. Samples of $1 \mathrm{~mL}$ were taken and diluted by a factor of 1:100 to be analyzed by HPLC.

\subsection{Citric acid adsorption conditions}

In order to determine the optimal conditions for citric acid adsorption with Dowex ${ }^{\mathrm{TM}}$ MARATHON ${ }^{\mathrm{TM}}$ WBA resin, a $3^{2}$ experiment design was developed. Selected factors were $\mathrm{pH}$ and temperature (Tab. 1). Temperature levels were chosen based on low operational cost and $\mathrm{pH}$ levels were chosen 
within the range of work of the resin reported by the manufacturer $(\mathrm{pH}: 0-7)$. The first $\mathrm{pH}$ value was selected lower than the first $\mathrm{pKa}$ value of citric acid $\left(\mathrm{pKa}_{1}=3.14\right)$ [17] and the other values were equally spaced in the work range of the resin for $\mathrm{pH}$.

Table 1. Factors and levels in $3^{2}$ factorial design of experiments.

\begin{tabular}{lllll} 
& \multicolumn{3}{c}{ Level } & \multirow{2}{*}{ Unit } \\
\cline { 2 - 4 } & -1 & 0 & 1 & \\
\hline $\mathrm{pH}$ & 1.5 & 4 & 6.5 & - \\
Temperature & 30 & 50 & 70 & ${ }^{\circ} \mathrm{C}$ \\
\hline
\end{tabular}

Nine vials containing $5 \mathrm{~g}$ the resin were prepared and 20 $\mathrm{mL}$ of synthetic fermentation broth were added. The composition of the synthetic fermentation broth was $6 \% \mathrm{~m} / \mathrm{v}$ of citric acid, $1 \% \mathrm{~m} / \mathrm{v}$ of sucrose, $1 \% \mathrm{~m} / \mathrm{v}$ of glutamic acid and $100 \mathrm{ppm}$ of each of the following salts: $\mathrm{MgSO}_{4}$, $\mathrm{Fe}_{2}\left(\mathrm{SO}_{4}\right)_{3},\left(\mathrm{Ca}\left(\mathrm{H}_{2} \mathrm{PO}_{4}\right)_{2}\right), \mathrm{K}_{2} \mathrm{SO}_{4}[20]$.

The response for the experimental design was defined as grams of citric acid adsorbed per gram of resin ( $\mathrm{g}$ citric acid/g resin). The factors for the design were the temperature and the $\mathrm{pH}$ of the media. The levels studied for the temperature were 30,50 and $70^{\circ} \mathrm{C}$; and for the $\mathrm{pH}$, were 1.5, 4.0 and 6.5. Concentrated sulfuric acid was employed to adjust the $\mathrm{pH}$ and the temperature was kept constant using a thermal bath for 24 hours. The concentration of citric acid in solution was determined by HPLC (section 2.6). The quantity of citric acid adsorbed was determined by mass balance, which represents the response of the experimental design. The data obtained was analyzed with the Software Minitab V18 with a significance level of $\alpha=0.05$.

\subsection{Packed column adsorption process}

A borosilicate column $($ ID $=2.5 \mathrm{~cm}$, height $=30 \mathrm{~cm})$ was packed with $48 \mathrm{~g}$ of Dowex ${ }^{\mathrm{TM}}$ MARATHONTM WBA resin. For the stream input and output control, tubing was placed in both ends of the column and the flows of all the feed solutions were controlled by the use of peristaltic pumps (Fig. 1).

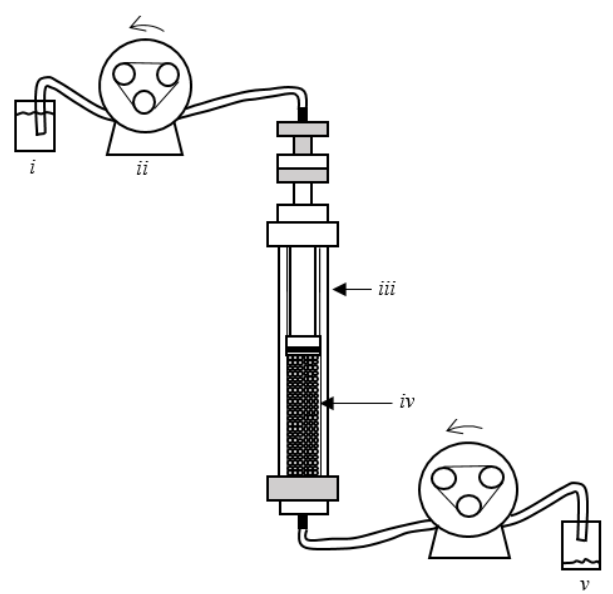

Figure 1. Packed column system configuration with ion-exchange resin: i) Feed solution, ii) Peristaltic pump, iii) Borosilicate column, iv) Dowex ${ }^{\mathrm{TM}}$ MARATHONTM WBA resin, v) Discharge stream collector.
The experiment was carried out in three stages: 1) Pretreatment: resin was pretreated with $0.1 \mathrm{M} \mathrm{NaOH}$ solution using a flow rate of $2 \mathrm{~mL} / \mathrm{min}$. Then the resin-packed column was washed with distilled water $(3 \mathrm{~mL} / \mathrm{min})$ until neutral $\mathrm{pH}$ was obtained. Once this $\mathrm{pH}$ was verified, the resin was activated and ready for the adsorption stage. 2) Citric acid adsorption: synthetic broth (section 2.4) was fed to the resinpacked column using a flow rate of $1.8 \mathrm{~mL} / \mathrm{min}$. Remaining synthetic broth was washed out of the resin-packed column using distilled water ( $3 \mathrm{~mL} / \mathrm{min})$. 3) Citric acid desorption: a sulfuric acid solution $(0.2 \mathrm{~N})$ was fed to the resin-packed column with a flow rate of $1.5 \mathrm{~mL} / \mathrm{min}$. The citric acid was recovered in the discharge of the column. Samples were taken from the discharge of resin-packed column for their analysis by HPLC (section 2.6) to determine the amount of citric acid recovered.

\subsection{Citric acid quantification by HPLC}

Citric acid was quantified using a Shimadzu Prominencei HPLC with a diodes detector and a reverse phase C-18 column (Teknokroma Brisa LC ${ }^{2} \mathrm{C} 18$, granulometry $5 \mu \mathrm{m}, 25$ $\mathrm{cm}$ long, diameter of $0.46 \mathrm{~cm})$. The HPLC analyses were carried out at a column temperature of $50{ }^{\circ} \mathrm{C}$. The wavelength used by the detector for the analyses was $210 \mathrm{~nm}$. The mobile phase used was a sulfuric acid solution in water at $0.01 \mathrm{M}$ [31]. The elution flow was $1 \mathrm{~mL} / \mathrm{min}$ and the injection volume was $10 \mu \mathrm{L}$. Every sample analyzed was compared with a calibration curve of citric acid solutions at concentration between $100 \mathrm{ppm}$ and $14000 \mathrm{ppm}$.

\section{Results and discussion}

\subsection{Resin selection}

The results of the preliminary comparison test are shown in Fig. 2. These indicated that the amount of citric acid adsorbed in MSA resin is about 50\% less than in WBA resin under the same operation conditions. Additionally, Fig. 2 shows the variation of citric acid concentration ( $g$ citric $\mathrm{acid} / \mathrm{meq}$ of active sites) in aqueous solution with time in both WBA and MSA resins. The adsorption of citric acid with MSA was faster than with WBA. For the weak base anion (WBA) resin, a plateau in adsorption is reached between 15 and $20 \mathrm{~min}$, indicating the saturation of the active sites. For the macroporous strong base anion (MSA) resin, the stabilization in the adsorption process starts around 10 $\min$.

The difference in the adsorption capacity of the studied resins is considered to be due to the strong base nature of the MSA resin, since stronger anion exchangers will adsorb other anions present in the complex mixture [17]. This phenomenon reduce their selectivity towards the desired compound and, as observed in Fig. 2, the total adsorption capacity of citric acid. 


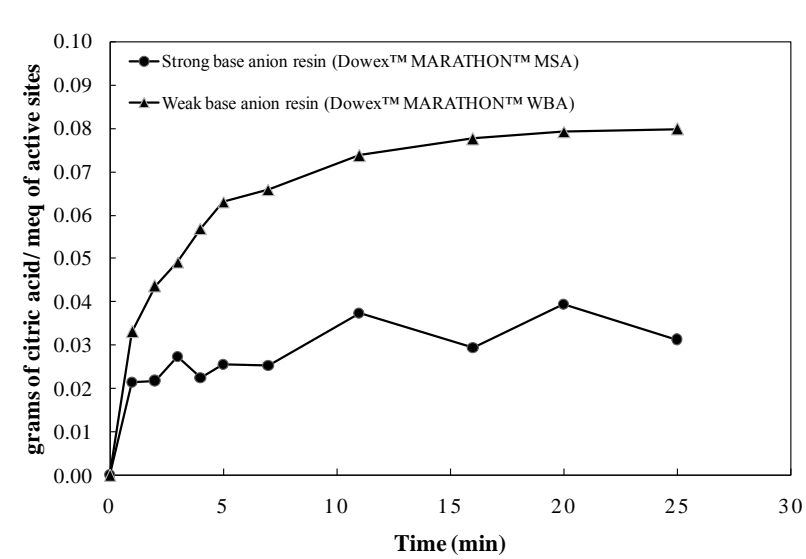

Figure 2. Comparison test between the MSA and WBA resins. Adsorbed citric acid is shown as the relation between grams of citric acid per miliequivalent of active sites in the resin.

Due to this preliminary screening result in the comparison test, the following experiments were carried out using only the WBA resin.

\subsection{Adsorption capacity of the WBA resin}

When low concentration aqueous solutions $(<4 \% \mathrm{~m} / \mathrm{v})$ of citric acid were analyzed approximately, 0.22 grams of citric acid were adsorbed from the solution by the resin without leaving significant quantities of acid $(<10 \%$ of the total citric acid). However, in high concentration aqueous solutions $(\geq$ $4 \% \mathrm{~m} / \mathrm{v}$ ) of citric acid, considerable quantities of citric acid remained without being adsorbed $(\approx 40 \%$ of the total citric acid in solution).

\subsection{Optimal operation conditions for the adsorption process}

The response function of the factorial design $3^{2}$ was defined as the citric acid concentration adsorbed on the WBA resin ( $\mathrm{g}$ citric acid/meq of active sites in the resin). Tab. 2 shows the response function, factors and levels used in the factorial design. The last column of Tab. 2 shows the citric acid adsorbed experimentally on the resin. The columns 2 - 3 show the coded levels $( \pm 1)$ for each factor, and the column 1 shows the run order for each experiment developed.

Table 2. Experimental design matrix: Factors, levels and response. The coding for the factors is as follows: $\mathrm{A}=\mathrm{pH}$ and $\mathrm{B}=$ temperature.

\begin{tabular}{|c|c|c|c|}
\hline \multirow{2}{*}{$\begin{array}{l}\text { Run } \\
\text { order }\end{array}$} & \multicolumn{2}{|c|}{ Factor } & \multirow{2}{*}{$\begin{array}{l}\text { Response (grams } \\
\text { of adsorbed citric } \\
\text { acid / meq of } \\
\text { active sites) }\end{array}$} \\
\hline & $\mathrm{pH}$ & Temperature & \\
\hline 1 & 0 & +1 & 0.0734 \\
\hline 2 & 0 & 0 & 0.0783 \\
\hline 3 & +1 & 0 & 0.0254 \\
\hline 4 & +1 & -1 & 0.0381 \\
\hline 5 & -1 & +1 & 0.1118 \\
\hline 6 & -1 & 0 & 0.1084 \\
\hline 7 & +1 & +1 & 0.0285 \\
\hline 8 & 0 & -1 & 0.0803 \\
\hline 9 & -1 & -1 & 0.1118 \\
\hline
\end{tabular}

The significance of the factor was determined by performing an Analysis of Variance (ANOVA). In order to determine the influence of the factor in the response, the $p$ value test was employed, using a significance level $\alpha=0.05$.

Results generated by Minitab v.18 indicated that temperature had no effect (statistical significance, $p>0.05$ ) in the temperature range studied of $30-70{ }^{\circ} \mathrm{C}$, and that the $\mathrm{pH}$ has statistical significance $(p<0.05)$ on the adsorption of citric acid on the WBA resin.

The response surface generated with experimental data (Fig. 3) indicate that for the lowest $\mathrm{pH}$ level $(\approx 1.5)$, adsorption of citric acid on the WBA resin is maximum. Any temperature level can be used, because the temperature effect (in the studied range) does not have a significant effect in the adsorption process of citric acid. These results are congruent with those obtained by Van der Bergh, Van de Voorde \& De Vos (2017). The protonation of dimethylamine functional groups is $\mathrm{pH}$ dependent. At low $\mathrm{pH}$ level (1.5), most of the citric acid is protonated and acid-base interaction can be performed with the resin functional groups. Subsequently, the citrate anion is attracted to the active sites of resin through Van Der Waals forces. At high pH level (6.5), acid-base interaction between the citric acid and resin is less intense and consequently the acid adsorption is weaker.

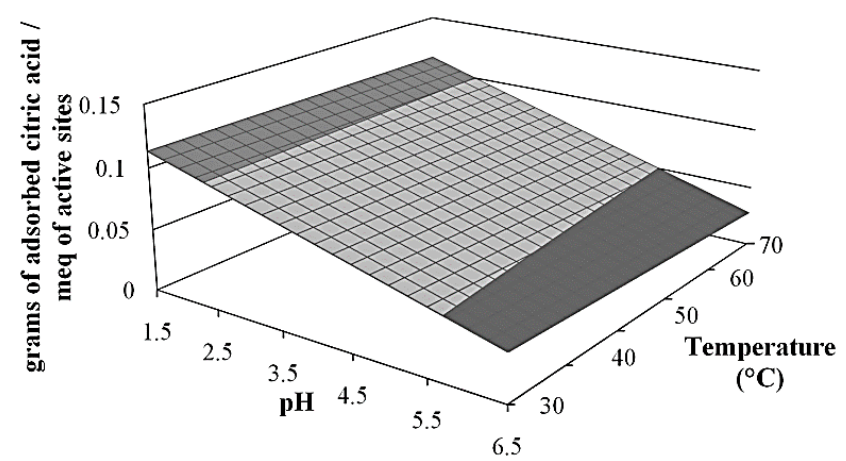

Figure 3. Response surface for the determination of optimal operation conditions in the adsorption process of citric acid in Dowex ${ }^{\mathrm{TM}}$ MARATHONTM WBA resin.

\subsection{Packed column adsorption}

The citric acid breakthrough curve was experimentally measured at room temperature (Figure 4). The results show that after $58 \mathrm{~min}$ the resin reaches the breakthrough point when the flow rate is $1.8 \mathrm{~mL} / \mathrm{min}$ and the $\mathrm{pH}$ of the feed is 1.8. The break point was defined as $\mathrm{C} / \mathrm{C}_{0}=0.05$, where $\mathrm{C}$ is the column discharge concentration of citric acid and $\mathrm{C}_{0}$ is the feed concentration of citric acid.

Experimental data of the breakthrough curve was fitted to the explicit mathematical model proposed by Ghorbanian et al. (2014), which has been employed in similar adsorption systems. Eq. 1 describes the explicit model, where $t$ is the time, $t_{F}$ is the time in which $C / C_{0} \approx 1$ and $D^{\prime}, E^{\prime}$ and $m$ are constants. The constants of the model were determined using 
the solver function of Excel 2016 and the resulting numerical values were: $D^{\prime}=34.75, E^{\prime}=191.46, m=-7.16$. The results of Eq. 1 are plotted in Fig. 4 and are in conformity with experimental data $\left(R^{2}=0.99\right)$.

$$
\frac{C}{C_{o}}=\frac{D^{\prime} \ln (1+t)}{E^{\prime}+\left(\frac{t}{t_{f}}\right)^{m}}
$$

The explicit model gives better results in the saturation state, but at the breakthrough point, the model slightly underestimates this condition.

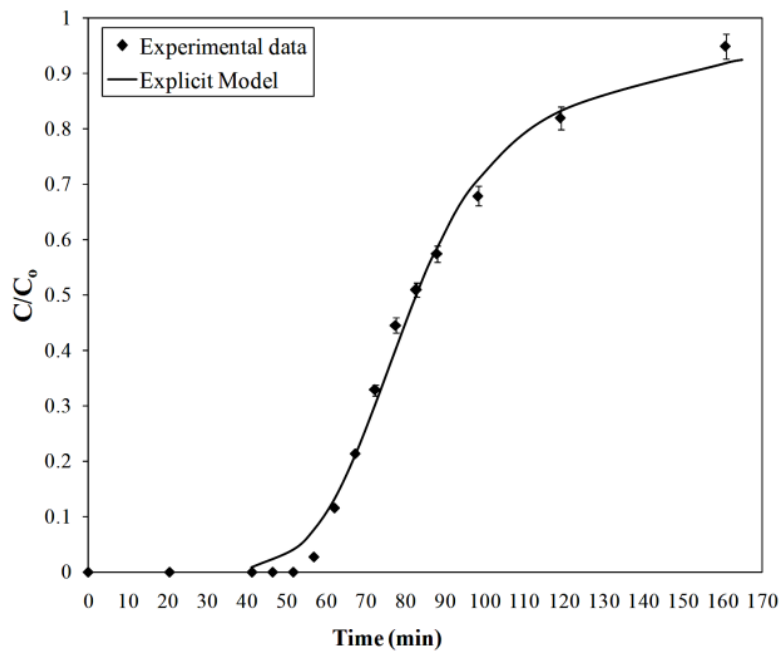

Figure 4. Breakthrough curve of the packed column in the adsorption process of citric acid at room temperature, $\mathrm{pH}$ of 1.8 , and flow rate of 1.8 $\mathrm{mL} / \mathrm{min}$.

Using the breakthrough curve (Fig. 4), the fraction of unused length of resin-packed column was also calculated. The value obtained indicates that $67 \%$ of resin in packed column was saturated when $\mathrm{C} / \mathrm{C}_{0}=0.05$. At 160 min, the saturation point is reached and $0.46 \mathrm{~g}$ of citric acid/g of resin were adsorbed. This result suggest that the Dowex ${ }^{\mathrm{TM}}$ MARATHON $^{\mathrm{TM}}$ WBA has a better adsorption capacity of citric acid than others studied adsorbents. As reported by Van der Bergh, Van de Voorde \& De Vos (2017), adsorption capacity of citric acid (g CA/g resin) at a $\mathrm{pH}$ value of 2 were 0.2 for IRA-900, 0.39 for IRA-67, 0.32 for PVP, 0.17 for Retardion 11A8, and 0.01 for PVPP.

In the desorption stage sulfuric acid was employed as desorbent. Samples collected at the discharge stream of the packed column were analyzed by HPLC and titration. Samples were first analyzed individually and then mixed to quantify the total amount of citric acid collected in the total volume of the discharge stream $(120 \mathrm{~mL})$. The results show that recovered citric acid in the desorption stage represents $82 \%$ of the citric acid in the feed solution, and it is recovered with a purity of $92 \%$ in solution. The impurities are probably due to the presence of compounds in the fermentation broth not identified in this work. Additionally, traces of sulfuric acid have been detected in collected fractions at the end of the desorption process, which reduces the purity of the citric acid in desorption solution.

\section{Conclusions}

Results indicate that the resin Dowex ${ }^{\mathrm{TM}}$ MARATHONTM WBA has a superior adsorption capacity of citric acid compared with the resin Dowex ${ }^{\mathrm{TM}}$ MARATHON ${ }^{\mathrm{TM}}$ MSA under the same operation conditions. The amount of citric acid adsorbed at the saturation point for the Dowex ${ }^{\mathrm{TM}}$ MARATHONTM WBA is 2.3 times higher than that for the Dowex $^{\mathrm{TM}}$ MARATHON ${ }^{\mathrm{TM}}$ MSA.

Through the factorial design, optimal conditions for the use of the Dowex ${ }^{\mathrm{TM}}$ MARATHONTM WBA resin in the recovery of citric acid were determined. The results showed that the best recovery rates are obtained at low $\mathrm{pH}(\approx 1.5)$ and that temperature has no effect on the adsorption process, in the temperature range analyzed $\left(30-70^{\circ} \mathrm{C}\right)$.

The separation process of citric acid from a synthetic mixture was evaluated using the resin Dowex ${ }^{\mathrm{TM}}$ MARATHONTM WBA. In this proposed method, recovery rate was $85 \%$ and the purity of the product was $92 \%$ (by HPLC). In addition, the reagents consumption was reduced as well as the waste streams generated compared to other processes such as the traditional recovery method by precipitation. Furthermore, the WBA resin presents a better adsorption capacity than other studied adsorbents used for citric acid recovery. Subsequently, the proposed method could be a technically feasible alternative for citric acid recovery at industrial scale.

\section{Acknowledgements}

This work was supported by USAID under Grant No. 0214405-G-2017-010-00.

We thank Gloria Gutiérrez, Gabriela Torres and Irene Ayala for their collaboration in the development of the experimental section of this research. We acknowledge Dow Chemical Co. for kindly supplying the ion-exchange resin.

"The authors declare no competing financial interest"

\section{References}

[1] W. Takatsuji and H. Yoshida, "Adsorption of Organic Acids on Weakly Basic Ion Exchanger: Equilibria," J. Chem. Eng. Japan, vol. 30, no. 3, pp. 396-405, 1997.

[2] N. Thakre, D. Datta, A. K. Prajapati, P. K. Chaudhari, and D. Pal, "Reactive Extraction of Citric Acid Using Different Extractants : Equilibrium, Kinetics and Modeling," Chem. Biochem. Eng. Q. J., vol. 31, no. 4, pp. 437-446, 2017.

[3] P. L. Show, K. O. Oladele, Q. Y. Siew, F. A. Aziz Zakry, J. C. W. Lan, and T. C. Ling, "Overview of citric acid production from Aspergillus niger," Front. Life Sci., vol. 8, no. 3, pp. 271-283, 2015.

[4] V. Suneetha, "High performance liquid chromatography analysis, production and brief comparative study of citric acid producing microorganisms from spoiled onions in and around Vellore 
district," Iran. J. Sci. Technol. Trans. A Sci., vol. 38, no. A2, pp. 193-197, 2014. G. S. Dhillon, S. K. Brar, M. Verma, and R. D. Tyagi, "Recent Advances in Citric Acid Bio-production and Recovery," Food Bioprocess Technol., vol. 4, no. 4, pp. 505-529, 2011.

[6] W. Boonkong, P. Sangvanich, A. Petsom, and N. Thongchul, "Comparison of an ion exchanger and an in-house electrodialysis unit for recovery of L-lactic acid from fungal fermentation broth," Chem. Eng. Technol., vol. 32, no. 10, pp. 1542-1549, 2009.

[7] J. M. González-Sáiz, M. A. Fernández-Torroba, and C. Pizarro, "Application of weakly basic copolymer polyacrylamide (Acrylamide-CO-N,N,'-dimethylaminoethyl methacrylate) gels in the recovery of citric acid," Eur. Polym. J., vol. 33, no. 4, pp. 475$485,1997$.

[8] I. N. Widiasa, P. D. Sutrisna, and I. G. Wenten, "Performance of a novel electrodeionization technique during citric acid recovery," Sep. Purif. Technol., vol. 39, pp. 89-97, 2004.

[9] A. M. Baniel, R. Blumberg, and K. Hajdu, "RECOVERY OF ACIDS FROM AQUEOUS SOLUTIONS," 1981.

[10] G. Annadurai, V. Raju, M. Chellapandian, and M. R. V. Krishnan, "Citric acid production," Bioprocess Eng., vol. 15, no. 6, pp. 323326, 1996.

[11] P. Pinacci and M. Radaelli, "Recovery of citric acid from fermentation broths by electrodialysis with bipolar membranes," Desalination, vol. 148, pp. 177-179, 2002.

[12] X. Sun, H. Lu, and J. Wang, "Recovery of citric acid from fermented liquid by bipolar membrane electrodialysis," J. Clean. Prod., vol. 143, pp. 250-256, 2017.

[13] A. Keshav, P. Norge, and K. L. Wasewar, "Reactive Extraction of Citric Acid Using Tri- $\mathrm{n}$-octylamine in Nontoxic Natural Diluents : Part 1 - Equilibrium Studies from Aqueous Solutions," Appl. Biochem. Biotechnol., vol. 167, pp. 197-213, 2012.

[14] M. Pazouki and T. Panda, "Recovery of citric acid - a review," Bioprocess Eng., vol. 19, pp. 435-439, 1998.

[15] A. Chandra, J. Ganesh, D. Tadimeti, and S. Chattopadhyay, "Transport hindrances with electrodialytic recovery of citric acid from solution of strong electrolytes," Chinese J. Chem. Eng., vol. 26, no. 2, pp. 278-292, 2018.

[16] G. S. Luo, X. Y. Shan, X. Qi, and Y. C. Lu, "Two-phase electroelectrodialysis for recovery and concentration of citric acid," Sep. Purif. Technol., vol. 38, pp. 265-271, 2004.

[17] C. S. López-Garzón and A. J. J. Straathof, "Recovery of carboxylic acids produced by fermentation," Biotechnol. Adv., vol. 32, no. 5, pp. 873-904, 2014.

[18] S. A. Ghorbanian, M. Davoudinejad, A. Khakpay, and S. Radpour, "Investigation of Breakthrough Curves of Citric Acid Adsorption," Chem. Biochem. Eng. Q. J., vol. 28, no. 3, pp. 329336, 2014.

[19] W. Jianlong, W. Xianghua, and Z. Ding, "Production of citric acid from molasses integrated with in-situ product separation by ionexchange resin adsorption," Bioresour. Technol., vol. 75, no. 3, pp. 231-234, 2000 .

[20] S. Kulprathipanja, H. Estates, A. R. Oroskar, D. Grove, and J. W. Priegnitz, "Separation of Citric Acid from Fermentation Broth with a Weakly Basic Anionic Exchange Resin Adsorbent," 1989.

[21] K. M. Long, G. S. Goff, S. D. Ware, G. D. Jarvinen, and W. H. Runde, "Anion exchange resins for the selective separation of technetium from uranium in carbonate solutions," Ind. Eng. Chem. Res., vol. 51, no. 31, pp. 10445-10450, 2012.

[22] K. Takao and T. Tsubomura, "Weakly-Basic Anion Exchange Resin Scavenges Impurities in Ionic Liquid Synthesized from Trialkyloxonium Salt," J. Chem. Eng. Data, vol. 57, pp. 24972502, 2012

[23] C. Marcu, D. Axente, and A. Balla, "Study of Fe ( III ) adsorption onto Dowex-Marathon resin, as a rate determining step of the U ( IV ) oxidation in 235 U enrichment column," J. Radioanal. Nucl. Chem., vol. 308, pp. 179-185, 2016.

[24] C. Marcu and D. Axente, "Kinetic and thermodynamic studies of U ( VI ) adsorption using Dowex-Marathon resin," J. Radioanal. Nucl. Chem., vol. 305, pp. 623-630, 2015.

[25] K.-H. Keil et al., "Isolation of enzymetically prepared carboxylic acids," EP0135728A1, 1983.

[26] L. Nie, J. Lu, W. Zhang, A. He, and S. Yao, "Ionic liquid-modified silica gel as adsorbents for adsorption and separation of watersoluble phenolic acids from Salvia militiorrhiza Bunge," Sep. Purif. Technol., vol. 155, pp. 2-12, 2015.

[27] M. Pan et al., "Separation of lactoperoxidase from bovine whey milk by cation exchange composite cryogel embedded macroporous cellulose beads," Sep. Purif. Technol., vol. 147, pp. 132-138, 2015.

[28] É. C. Cren, L. Cardozo Filho, E. A. Silva, and A. J. A. Meirelles, "Breakthrough curves for oleic acid removal from ethanolic solutions using a strong anion exchange resin," Sep. Purif. Technol., vol. 69, no. 1, pp. 1-6, 2009.

[29] W. Yuan, M. Wiehn, Y. Wang, H. Woo Kim, B. E. Rittmann, and D. R. Nielsen, "Solid-phase extraction of long-chain fatty acids from aqueous solution," Sep. Purif. Technol., vol. 106, pp. 1-7, 2013.

[30] M. Van den Bergh, B. Van de Voorde, and D. De Vos, "Adsorption and Selective Recovery of Citric Acid with Poly(4vinylpyridine)," ChemSusChem, vol. 10, no. 24, pp. 4864-4871, 2017.

[31] M. A. Romero Rodríguez, M. L. Vázquez Oderiz, J. López Hernández, and J. Simal Lozano, "Determination of Vitamin C and Organic Acids in Various Fruits by HPLC," J. Chromatogr. Sci., vol. 30, no. November, pp. 433-437, 1992. 